\title{
AS ESPECIFICIDADES NA FORMACִ̃̃O DO EDUCADOR DE JOVENS E ADULTOS: UM ESTUDO SOBRE PROPOSTAS DE EJA
}

Leôncio Soares*

RESUMO: Este artigo traz resultados de uma pesquisa que vem sendo realizada sobre as especificidades da formação do educador de jovens e adultos em que buscamos selecionar propostas que nos auxiliassem a identificar suas singularidades. De acordo com o tempo de existência, histórico, tradição, impacto na área e a relevância para a comunidade envolvida, elegemos as quatro propostas a serem visitadas: o Projeto Escola Zé Peão, o Projeto Paranoá, o PROEF e o CMET Paulo Freire. Ao analisarmos como acontece a EJA e o que ressaltou quanto às suas especificidades, nas propostas pesquisadas, oito pontos se destacaram: a origem de cada um; a diversidade dos sujeitos; a preocupação com o espaço físico; as formas de conceber as propostas curriculares; a disponibilidade de recursos didáticos; as políticas complementares de alimentação e transporte; a formulação de uma política pública para a EJA; e as iniciativas de formação inicial e continuada.

Palavras-chave: Especificidades; Formação do Educador; EJA.

\section{THE SPECIFICITIES IN THE FORMATION OF THE TEACHER}

\section{OF THE YOUNG AND ADULT STUDENTS: A STUDY ON THE EJA PROPOSAL}

ABSTRACT: This article brings out the results of a research that has been realized about the specificities of the Young and Adults educators' formation, in which we sought to select proposals to help us indentifying the singularities of those educators. We elected the four proposals to be visited according to their time of existence, their historic, their tradition, their impact on the area and their relevance for the community involved. They are: the Project "Escola Zé Peão", the Project "Paranoá", the "PROEF" and the "CMET Paulo Freire". By analyzing how EJA takes place in each proposal studied and what came out about their specificity, we can stress eight points: the origin of each project, the diversity of the subjects, the caution with the physical space, the way of conceiving the circular proposals; the availability of didactical resources; the complementary politics of food and transportation; the public policy formulation for EJA and the initiatives of initial and continued formation.

Keywords: Specificities; Educator's Formation; EJA.

* Professor do curso de Pedagogia e do Programa de Pós-Graduação em Educação da Faculdade de Educação da Universidade Federal de Minas Gerais (UFMG); Membro do Núcleo de Educação de Jovens e Adultos dessa faculdade e do Fórum Mineiro de EJA. E-mail: formacaoeja@yahoo.com.br 


\section{Introdução}

Atualmente, a EJA está sendo configurada e, segundo Arroyo, "se partirmos da hipótese de que o perfil do educador desses sujeitos se estruturará a partir dessa configuração" (ARROYO, 2006), necessário se faz pensar, pesquisar e refletir sobre as propostas de formação desses educadores. Este texto traz resultados parciais de uma pesquisa que, constantemente, é realizada sobre as especificidades da educação de jovens e adultos. Os estudos e as pesquisas sobre a área apontam para a fase de transição que a EJA atravessa. Depois de um longo período em que "a União progressivamente abandonou as atividades dedicadas à educação de jovens e adultos analfabetos" (BEISIEGEL, 1997), fora das prioridades das ações políticas (DI PIERRO, 2004), o movimento em torno da EJA resgata sua importância, inscrevendo-a nas pautas das políticas públicas. Para Haddad (2007), esse período tem significado avanços na maneira de pensar e de fazer, o que evidencia sinais de uma nova forma de fazer EJA:

Avançar numa nova concepção de EJA significa reconhecer o direito a uma escolarização para todas as pessoas, independentemente de sua idade. Significa reconhecer que não se pode privar parte da população dos conteúdos e bens simbólicos acumulados historicamente e que são transmitidos pelos processos escolares. Significa reconhecer que a garantia do direito humano à educação passa pela elevação da escolaridade média de toda a população e pela eliminação do analfabetismo (HADDAD, 2007, p. 15).

O tema das especificidades na educação de jovens e adultos é muito amplo. Pesquisadores, educadores e educandos da EJA reconhecem que essa modalidade de educação tem suas peculiaridades (ARROYO, 2006; SOARES, 2007). Em referência feita por Ribeiro (1999), sobre análise realizada por Oliveira (1998), foi evidenciada a falta de formação específica para educadores de EJA:

Num universo de 198 trabalhos catalogados como parte deste estudo, Oliveira (1998) identificou 23 cuja temática contempla a formação e a prática docente, verificando que a grande maioria identifica a falta de formação especifica dos educadores como um dos principais entraves das experiências educativas (RIBEIRO, 1999, p. 185). 
Em pesquisa anterior, na qual estudamos as habilitações em EJA dos cursos de Pedagogia do Brasil, procuramos compreender como se dava a formação inicial desses educadores, abordando questões sobre a inserção profissional e a avaliação dos egressos sobre o curso, suas contribuições e limites, tendo como referência o trabalho com a EJA (SOARES, 2007; 2008).

No processo de escuta dos entrevistados, eram recorrentes os questionamentos sobre a existência de uma especificidade na EJA que indicava a necessidade de uma formação própria para seus educadores. A análise desses relatos remeteu-nos à pergunta: afinal, que especificidades são essas continuamente mencionadas? Como caracterizá-las? Como definilas? Essas interrogações nos instigaram a abordar, na pesquisa atual, as especificidades na formação do educador de jovens e adultos. Ribeiro (1999) alerta-nos da importância de realizar estudos voltados para a produção e a sistematização de conhecimentos que contribuam para a formação dos educadores de EJA:

Considerando que a insuficiência da formação dos professores já foi suficientemente reiterada nos estudos acadêmicos, seria oportuno que esses estudos passassem a se concentrar mais na produção e na sistematização de conhecimentos que contribuam no plano teórico para constituição deste campo pedagógico e, consequentemente, para a formação de seus educadores (RIBEIRO, 1999, p. 190).

Nesse sentido, procuramos conhecer como a formação acontece por meio das atividades de extensão universitária, formação continuada e especialização, para que caminhássemos na identificação de suas peculiaridades.

Inicialmente, para localização e mapeamento da existência de propostas de EJA, houve consulta ao banco de dados do MEC/INEP, dos participantes do GT de EJA da ANPEd, dos presentes ao I e ao II Seminário de Formação do Educador de Jovens e Adultos, da relação dos ENEJAs de 2005, 2006, 2007 e 2008 e ao Portal dos Fóruns. De posse dos contatos, solicitamos documentos às instituições, tais como projetos, relatórios ou ementas das atividades desenvolvidas. O processo foi moroso, pois nem sempre obtivemos uma resposta rápida dos professores ou pesquisadores.

A análise inicial dos materiais recebidos das instituições revelou pouca clareza das ações, o que nos levou a restabelecer e manter contatos 
em busca de mais informações e detalhamento dessas ações. Além do estudo e da análise dos projetos recebidos, procuramos por registros e publicações que apresentassem relatos de atuação e/ou formação de educadores de jovens e adultos.

De um total de 63 instituições em que identificamos a existência de alguma atividade de EJA, obtivemos informações de 18, por meio de materiais que variavam entre relatórios, projetos escritos para a pró-reitoria de extensão e descrição de atividades, caracterizando as ações na área de Educação de Jovens e Adultos. Esses projetos estavam distribuídos nas cinco regiões geográficas do país da seguinte forma: região Sudeste com 23 projetos, Nordeste com 18, Sul com 13, região Norte com cinco projetos e, por fim, Centro-Oeste com quatro projetos.

Identificamos uma diversidade de atividades relacionadas à EJA como projetos e programas ora de alfabetização, ora de escolarização de jovens e adultos. Ademais, foram encontrados cursos de formação de educadores por meio de extensão, da formação continuada e de especialização em EJA. Em algumas instituições, o processo de formação do educador se dá vinculado à prática desenvolvida nos projetos. Algumas ações são identificadas como iniciativas da própria universidade, outras vezes são promovidas a partir de parcerias com as instâncias governamentais. Como iniciativa própria, encontra-se a oferta de disciplinas obrigatórias ou optativas nos cursos de graduação em Pedagogia e demais licenciaturas. Muitas dessas iniciativas estão associadas ao surgimento de grupos ou núcleos de educação de jovens e adultos que, entre outras iniciativas, organizam ações em que são ofertados cursos de formação, elaboram materiais para a EJA, realizam avaliações e socializam estudos e pesquisas. Também, em análise inicial, percebe-se que, entre as IES pesquisadas, a maioria tem atividades de EJA ora demandadas por municípios, ora por governos estaduais, ora por programas de iniciativas do governo federal. Perante a diversidade de projetos, vislumbrou-se a possibilidade de conhecer alguns in loco. Como indicadores de critérios para seleção das observações de campo, consideramos o tempo de existência da proposta, o histórico e a tradição, e o impacto na área. Interessava-nos ainda encontrar projetos de formação elaborados a partir da experiência das propostas, valorizando espaços que possuíam continuidade e regularidade, considerando o número de educadores e educandos nas atividades e sua relevância para a comunidade envolvida. $\mathrm{O}$ tempo de existência foi 
considerado aspecto importante na seleção dos espaços a serem analisados, por acreditarmos que os projetos com maior longevidade poderiam ter acumulado mais experiência e estruturado melhor a proposta de formação de seus educadores.

Outro critério utilizado foi identificar iniciativas em diferentes regiões do país, para que houvesse uma análise mais panorâmica, evitando a limitação a algumas regiões. Consideramos também a experiência de produção de material didático próprio, partindo do pressuposto de que essa prática afeta diretamente a formação dos educadores e se relaciona com a abordagem de aspectos que são característicos do público e do trabalho com a EJA.

Selecionamos inicialmente três propostas para realizar observação de campo: o Projeto Escola Zé Peão, na UFPB; o Projeto Paranoá, na UnB; e o PROEF, na UFMG. Posteriormente, também foi selecionado o CMET Paulo Freire - Centro Municipal de Educação do Trabalhador, do município de Porto Alegre.

No período em que estivemos nas instituições, coletamos dados sobre a formação dos educadores e realizamos entrevistas com coordenadores e educadores, além de conhecer seus espaços de formação e suas atividades. As entrevistas possibilitaram perceber, na perspectiva dos sujeitos, as contribuições e os limites da formação quando se referiam à prática com educandos da EJA.

O contato direto com os projetos por meio da observação dos espaços, das conversas com educadores, acompanhamento de reuniões de formação e de aulas ministradas permitiu-nos perceber motivações, emoções, sentidos e significados atribuídos pelos educadores ao trabalho com a EJA, o que ainda não havia sido identificado nos contatos anteriores.

\section{A EJA tem especificidades! E a formação dos educadores?}

A construção de uma proposta de trabalho que reconheça as especificidades do público da EJA perpassa diversos aspectos como: a diversidade de sujeitos educandos com características peculiares; a preocupação com a existência de uma infraestrutura que acolha a realidade desse público; a elaboração de propostas curriculares que vá ao encontro das necessidades, das exigências e dos interesses desses sujeitos, incluindo 
a flexibilidade dos tempos e espaços; a disponibilidade de recursos didáticos que atendam e desenvolvam as potencialidades desses sujeitos; as iniciativas de formação inicial e continuada de educadores; políticas compensatórias de alimentação e transporte que favoreçam a permanência dos educandos.

Com a pesquisa que deu origem a este artigo, buscamos identificar o que é específico da formação dos educadores de jovens e adultos. Por isso, ao analisar as propostas, focamos o que de específico da EJA está presente em seus projetos. Uma fala recorrente dos educadores e coordenadores entrevistados se referia às características da formação dos educadores no que diz respeito às necessidades, aos desejos e aos limites dos educandos.

(...) Então essa formação desse modo que agente faz, também conscientizadora, problematizadora, dando muita ênfase ao perfil do educando e de educador, é que a gente precisa ser pra dar resposta à necessidade desse educando. Que não é só de escolarização né, esse é o desejo maior deles, mas é uma série de outras coisas que precisam ser dado conta né, do medo, da insegurança, da baixa autoestima né, de... da ignorância, e muitas vezes aquela rudeza é uma defesa né, de falar alto de... é uma defesa né ${ }^{1}(. .$.

\section{As propostas analisadas}

Percebemos que a realização de um trabalho adequado à EJA requer que a instituição tenha uma organização própria voltada ao atendimento das necessidades de seus educandos.

A primeira proposta analisada foi a do Projeto Escola Zé Peão², que está localizado na cidade de João Pessoa, na Paraíba. O projeto foi escolhido por atender aos critérios de seleção e por suas características particulares. A observação possibilitou conhecer os espaços de ensino e de formação dos educadores, coletar material impresso e publicações, bem como, realizar as entrevistas com os coordenadores e educadores do Projeto. A proposta atende aos trabalhadores da construção civil, cuja maioria é constituída de migrantes que trabalham durante a semana em João Pessoa e retornam, na sexta-feira, para suas cidades de origem, no interior da Paraíba. Devido à realidade desses trabalhadores, as aulas acontecem nos canteiros de obras de segunda a quinta-feira à noite, e as sex- 
tas-feiras ficam reservadas para atividades de planejamento e formação da equipe pedagógica.

A proposta de trabalho do Zé Peão passou a se organizar a partir de três programas básicos: Alfabetização na primeira laje APL, destinado aos operários sem escolarização prévia; Tijolo sobre tijolo - TST para aqueles com certo domínio da leitura, escrita e matemática; Varanda Vídeo - VV, objetivando contribuir para a formação cultural mais ampla do trabalhador/aluno, por meio de exibição e discussão de vídeos. A partir de 1995, contou também com a biblioteca volante e um programa de atividades e visitas culturais. Durante a observação de campo do Projeto Escola Zé Peão, foram realizadas dez entrevistas, compreendendo coordenadores, educadores, pesquisadores e professores universitários. Juntamente com a realização dessas entrevistas, observamos um canteiro de obras e pudemos acompanhar a aula em uma turma de Alfabetização na Primeira Laje e em uma turma de Tijolo Sobre Tijolo. Além disso, foi possível acompanhar uma reunião de formação e planejamento das educadoras, que nos permitiu visualizar a dinâmica desse processo.

A segunda observação de campo, ocorrida no mês de agosto de 2009, teve por objetivo conhecer o Projeto Paranoá, localizado na cidade satélite de mesmo nome no Distrito Federal que, por sua vez, tem sua fundação marcada pela luta da comunidade pelo direito de permanecer no local e por melhores condições de vida. Igualmente à primeira visita, realizamos as entrevistas, bem como conhecemos o espaço de realização das aulas e da formação dos educadores, coletamos materiais e publicações.

O projeto possui cinco turmas, entre elas: iniciantes, intermediários e concluintes, que funcionam no CEDEP - Centro de Desenvolvimento do Paranoá. Ele se organiza para capacitar os professores, que, sendo moradores da cidade, assumirão turmas de jovens e adultos. Além disso, a proposta possibilita aos alunos da $\mathrm{UnB}$ a inserção como monitores na sala de aula vinculada à pesquisa, que pode resultar em trabalhos de monografia e de pós-graduação.

Durante nossa observação de campo, fizemos seis entrevistas, com coordenadoras, alfabetizadoras do projeto e estudante de graduação da UnB. Realizou-se, também, um grupo focal com educandos do projeto. Participamos, ainda, do Fórum - momento de formação em que participam educandos e educadores do Paranoá e estudantes da UnB. 
A terceira observação de campo foi no Centro Municipal de Educação do Trabalhador Paulo Freire - CMET, escola da rede municipal de Porto Alegre que atende a EJA nos três turnos. A escolha dessa escola deveu-se ao fato de ter sido selecionada para a pesquisa nacional realizada pela Ação Educativa (MOLL; VIVIAN, 2007)3. Durante a visita, foram realizadas onze entrevistas, incluindo responsáveis pela EJA no município, coordenadores pedagógicos, coordenadora cultural, coordenador de turno, educadoras e educando.

A última observação de campo foi realizada no Projeto de Ensino Fundamental de Jovens e Adultos - PROEF, criado em 1985 por um grupo de professores da Faculdade de Letras da UFMG que desenvolvia uma pesquisa com o objetivo de analisar o processo de alfabetização pelo viés da linguística. Esse grupo trabalhou com as primeiras turmas de Jovens e Adultos funcionários da UFMG. Interrompido em 1989, esse trabalho foi retomado em 1994, na Faculdade de Educação, sob a coordenação do Núcleo de Educação de Jovens e Adultos - NEJA - e do Centro de Alfabetização Leitura e Escrita - CEALE. Atualmente, a UFMG conta com um Programa de Educação Básica de Jovens e Adultos que compreende os seguintes Projetos: PROEF 1 (primeiro segmento do ensino fundamental), PROEF 2 (segundo segmento do ensino fundamental) e PEMJA (ensino médio).

\section{Reflexões sobre as propostas analisadas}

Ao analisar como acontece a educação de jovens e adultos nas propostas pesquisadas e, em especial, o que se ressaltou quanto às especificidades da EJA, oito aspectos sobressaíram, merecendo ser aprofundados em estudos posteriores.

O primeiro aspecto se refere ao surgimento da cada projeto. A origem de cada uma das propostas é marcada por algumas convergências: as quatro nasceram praticamente no mesmo período, final da década de 1980 e início da década de 90 . O contexto daquele momento foi de resistência e de conquistas, em que a sociedade esteve mobilizada em prol da redemocratização, cujo auge foi a Constituição de 1988. O surgimento do Projeto Paranoá ilustra esse período de conquista dos sujeitos, que resultou da mobilização e na resistência, desde a garantia ao direito de mora- 
dia e ao direito à educação. Segundo Jesus (2007), para os moradores, a conquista de permanecer no local, apesar de várias tentativas de expulsão, tornou-se uma vitória. O Projeto de Educação de Jovens e Adultos do Paranoá teve seu início com o Mobral, em 1986, e foi interrompido três meses depois. Mas os participantes que estavam no projeto, moradores da cidade do Paranoá, reivindicaram sua continuidade. As organizadoras e coordenadoras da associação de bairro, atual Cedep, procuraram a UnB para obter orientações de como dar continuidade ao projeto,

(...) Quem procurou a UnB pra vir pra cá, fomos nós. Nós fomos lá e falamos: "Oh, nós queremos que vocês nos ajudem a fazer algo diferente". Então quando a gente foi buscar, a gente já disse: "Olha nós não sabemos o que fazer e como fazer, nós temos que aprender como fazer”. Nós sabemos que temos que fazer, queremos, tínhamos a consciência de que tínhamos de fazer algo diferente, que não era aquela coisa do Mobral, só de ficar lá, sabe, encher o quadro, aquela coisa. Mas nós não sabíamos como fazer, aí nós fomos lá e falamos para a Maria Alice, quando ela decidiu vir pra cá, nós queremos aprender como fazer. Aí já começou a nossa formação. (.... $)^{4}$

O projeto surge com o objetivo não somente de alfabetizar, mas de transformar os moradores em sujeitos críticos e conscientes dos seus direitos. Está voltado para o enfrentamento de situações-problemas desafios que são discutidos e selecionados por todos do projeto, educandos, coordenadoras, alfabetizadoras e alunos da UnB - num fórum realizado semanalmente e desenvolvido na semana seguinte (JESUS, 2007).

No caso do CMET, sua história está diretamente relacionada às ações do Serviço de Educação de Jovens e Adultos - SEJA, uma proposta de política pública da Secretaria Municipal de Educação de Porto Alegre - SMEd, que visava a atender alunos e alunas que eram fundamentalmente trabalhadores (SEJA, 1998). As atividades do CMET tiveram início em 1989, com quatro salas de aula, funcionando nos três turnos, no Mercado Público da cidade, e seus professores eram concursados da prefeitura. Com a reforma do Mercado, em 1990, essas turmas de EJA ficaram sem um local, "desalojadas", iniciando assim uma luta pela conquista de um espaço físico. Para que as aulas não tivessem fim, os alunos e professores, após muitas solicitações e reivindicações na prefeitura, conseguiram que alguns locais públicos cedessem salas para que as aulas acontecessem. Somente em 2000, por meio do orçamento participativo, a comunidade escolar conquistou o prédio em que estão desde então. 
A diversidade dos sujeitos de cada uma das ações pesquisadas é o segundo aspecto a ser analisado. Segundo ARROYO (2006, p. 22), esses educandos "são jovens e adultos com rosto, com histórias, com cor, com trajetórias sócio-étnico-raciais, do campo, da periferia".

De acordo com Giovanetti (2005), o que caracteriza a EJA é a presença de jovens e adultos de origem popular, marcados por processos de exclusão social, marginalização cultural e exploração econômica. Dessa forma, as propostas educacionais que têm como referência a educação popular focam essa singularidade ao conceber a educação como processo voltado para o resgate da "humanidade roubada" (FREIRE, 2000).

Os alunos da EJA, ao vivenciarem, pelo viés da exclusão social, o agravamento das formas de segregação - cultural, espacial, étnica, bem como, das desigualdades econômicas -, experimentam, a cada dia, o abalo de seu sentimento de pertencimento social, o bloqueio de perspectivas de futuro social (FREIRE, 2000, p. 254).

Os sujeitos dos projetos pesquisados apresentam características que lhes são bem peculiares. No caso do Zé Peão, são trabalhadores da construção civil, em sua maioria migrantes. O CMET, além de atender jovens acima de 14 anos e trabalhadores em geral, recebe, nos turnos manhã e da tarde, senhoras e alunos com necessidades educativas especiais, como surdos, cegos e com deficiência mental. No caso do Projeto Paranoá, os sujeitos são os moradores da comunidade. Já o PROEF atende os funcionários da UFMG, os trabalhadores terceirizados e a comunidade externa.

O terceiro aspecto diz respeito à preocupação com a existência de um espaço físico que acolha a realidade desse público. O início de muitos projetos e programas de EJA se dá em instalações precárias ou ociosas, exigindo frequentes adaptações e "otimizações" de espaço, como nos casos das classes noturnas. A história do CMET Paulo Freire exemplifica essa trajetória, em que a conquista do espaço próprio significou uma adequação às necessidades e exigências da realidade dos sujeitos, como, por exemplo, o atendimento aos portadores de necessidades especiais.

No PROEF, os espaços utilizados são os do Centro Pedagógico e da Faculdade de Educação da UFMG, e os recursos de ambos estão disponíveis para os alunos jovens e adultos. Já o Zé Peão tem outra realidade. Sendo o canteiro de obras local de trabalho e de moradia, são os edu- 
cadores que se deslocam para aulas do Projeto, a fim de facilitar a participação dos educandos da construção civil. Por acontecer em espaços atípicos, sempre requer improvisações. Mesmo não sendo um local apropriado para as aulas, a opção por utilizá-lo condiz com a necessidade e a realidade dos sujeitos.

As formas de conceber as propostas curriculares e de associá-las à realidade dos sujeitos concretos é o quarto aspecto de análise. Para Haddad, a flexibilidade dos tempos e espaços implica uma nova forma de fazer EJA:

A flexibilidade nos horários de entrada e saída, a não-cobrança de presença, a frequência de acordo com o desempenho e/ou interesse em uma disciplina ou projeto, ou campo de interesse, tudo isso aponta para uma forma de conceber a escola e o seu currículo que, no limite, indicam sinais para uma nova forma de fazer EJA, superando o modelo tradicional, cuja reposição acelerada do currículo do ensino regular é a principal característica, e os alunos tratados de forma homogênea, classificados por séries (HADDAD, 2007, p. 17).

As experiências analisadas, de alguma forma, procuraram atender às particularidades do público da EJA. Em função da diversidade dos sujeitos, a educação nesses locais se caracteriza pelos espaços e tempos diferenciados de construção de conhecimentos. O regimento do CMET já apresentava essa questão:

(...) Para que todos tenham acesso, permanência e qualidade na escolarização correspondente ao Ensino Fundamental e no trabalho com o currículo nãoformal, é imprescindível um currículo diverso, dinâmico assim como professores, equipe diretiva e multidisciplinar especializados e capacitados para a concretização da proposta político - administrativo - pedagógica e cultural do $\operatorname{Centro.~}^{5}(\ldots)$

No Zé Peão, essa iniciativa se constitui a partir de uma contínua tomada de decisões, que leva o currículo a adotar, como ponto de parti$\mathrm{da}$, a tentativa de relacionar a socialização do saber sistematizado com a experiência dos trabalhadores. O currículo se baseia em três princípios básicos: a contextualização, a significação operativa e a especificidade escolar. O princípio da contextualização se volta ao reconhecimento da realidade em que o projeto se situa, da vida dos trabalhadores da construção civil, das lutas do sindicato e das teorizações sobre educação e alfabe- 
tização, em particular. A significação operativa consiste na busca pelo confronto entre o desejável e o possível, e o da Especificidade Escolar defende o compromisso com o ensino da leitura e da escrita e equilíbrio com as atividades diversificadas.

O currículo do CMET trabalha na perspectiva das Totalidades de Conhecimento do SEJA, cujo trabalho educativo é organizado de forma que as partes que compõem o ato educacional estejam permanentemente conectadas entre si. A visão de conhecimento como totalidade, de acordo com as coordenadoras da escola, estrutura o ensino de forma global, de maneira que o conhecimento seja construído e aprofundado em níveis crescentes e articulados entre si. No CMET, a organização curricular está fundada sobre três concepções fundamentais, respaldadas no ideário da educação popular e do construtivismo interacionista: interdisciplinaridade, formação do senso crítico e o aluno como ser-presente.

O quinto aspecto a ser considerado é a disponibilidade de recursos didáticos que atendam e desenvolvam as potencialidades desses sujeitos. Ainda que de forma dispersa, muitos recursos pedagógicos para jovens e adultos são produzidos, como materiais impressos e vídeos, produção avulsa ou coleções. No Projeto Escola Zé Peão, partiu-se da realidade dos trabalhadores da construção civil para a elaboração de um texto contendo características de suas histórias de vida. Acompanhando essa história, foi construído um texto didático com atividades pedagógicas a serem trabalhadas nos canteiros de obra. No CMET, já houve uma produção, a partir dos textos elaborados pelos educandos, intitulada Palavra do Trabalhador ${ }^{6}$ (SILVA, 2007). De posse dessa produção, os professores levavam os textos dos educandos para serem lidos e analisados em sala de aula. A chegada dos educandos cegos ao CMET motivou os educadores a prepararem material apropriado, que contribuísse para o desenvolvimento de atividades didático/pedagógicas. Os depoimentos de alunos e professores mostraram o quanto essa produção foi significativa para a prática pedagógica.

Porque esses alunos que chegam pra nós, também deficientes visuais ou com baixa visão, eles têm que ter todo um atendimento especial no (falta o local), porque a escrita deles é em braile, eles têm que fazer contas usando outro materialzinho que eles usam pra escrever também é diferente, então eles têm que ter todo um suporte que a gente teve que buscar aí hoje nós temos dois profissionais na escola, locados na escola que dão esse suporte pra esses alunos e pro professor em sala de aula saber como trabalha. ${ }^{7}$

Educação em Revista | Belo Horizonte | v.27 | n.02 | p.303-322 | ago. 2011 
O sexto aspecto apresenta as políticas compensatórias de alimentação e transporte e sua importância para a permanência dos educandos. Se a conquista de vagas para jovens e adultos é uma concretização do direito à educação, a permanência desses alunos na escola depende da qualidade dessa oferta. Uma política que venha ampliar os avanços já conquistados, considerando a dura realidade desses sujeitos, certamente contribuirá para a permanência dos educandos e a qualidade da educação. Constam dessa ampliação a alimentação e os meios de transporte que possibilitam o acesso até a escola. Nos casos dos projetos Paranoá e Escola Zé Peão, a localização próxima à moradia dos sujeitos atendidos favorece a presença constante na escola. A localização do CMET na região central de Porto Alegre é um fator que facilita o deslocamento do trabalho até a escola, e desta para as residências dos alunos. $\mathrm{O}$ mesmo já não ocorre no caso do PROEF, que, por estar localizado em uma das regiões da cidade de Belo Horizonte, dificulta o deslocamento dos estudantes entre o trabalho, a escola e sua residência. Essa situação se agrava devido à inexistência de passe-escolar, encarecendo o custeio de seus estudos.

A formulação de uma política pública para a educação de jovens e adultos que contemple a garantia do direito à EJA e efetive sua oferta com qualidade é o sétimo aspecto. De acordo com Fávero:

\footnotetext{
Não apenas uma segunda oportunidade de escolarização, em termos do que se critica como uma "educação pobre para os pobres", mas outras formas de educação que venham a instrumentalizar indivíduos e grupos para, dizendo novamente: entender e criticar a realidade em que vivem e, em consequência, propor alternativas para sua transformação. Não mais meras e repetitivas campanhas de alfabetização, nem ofertas facilitadas do ensino copiado do sistema regular, mas ações educativas que preparem para a vida, para uma nova vida, ao longo de toda a vida (FÁVERO, 2009, p. 91).
}

Entre os desafios a serem enfrentados na formulação de políticas públicas encontra-se a profissionalização dos educadores. A falta de concurso público direcionado à EJA contribui para que o campo reproduza o amadorismo e o improviso no enfrentamento de suas questões. Segundo Schmelkes (2008, p. 372), o "gargalo" da educação de adultos está na falta de profissionalização do serviço:

El gran cuello de botella para el logro de servicios de educación de adultos más relevantes, eficientes y de calidad se encuentra en la falta de profesiona- 
lización en todos los niveles, pero muy especialmente entre los que cumplen funciones de agentes educativos. Sin un servicio de carácter profesional y sin agentes educativos de calidad debidamente preparados y adecuadamente capacitados, todo lo que hemos venido diciendo tiene pocas posibilidades de traducirse en un servicio efectivo.

Uma das explicações para a experiência bem sucedida do CMET é o fato de seus professores serem concursados, fazendo parte do quadro de funcionários da prefeitura de Porto Alegre. No início das atividades da escola, na década de 1990, para se trabalhar com a EJA, os educadores, após a seleção por concurso, ainda passavam por uma seleção interna, sendo assim, muitos dos professores entrevistados na visita à escola passaram por essa seleção. Grande parte dos educadores está desde o início no CMET, há quase 20 anos. Dessa forma, percebe-se a cumplicidade de toda comunidade escolar, um sentimento de equipe que colabora para o desenvolvimento das atividades. Boa parte dos educadores possui especialização na área de educação de jovens e adultos, e outros, mestrado e até doutorado. A coordenação escolar entende que a formação de seus professores deve ser contínua, pelo fato de o CMET ser uma escola que recebe uma diversidade de sujeitos.

O oitavo aspecto abrange as iniciativas de formação inicial e continuada de educadores. Em pesquisa realizada anteriormente, Soares (2007) apontou a necessidade de uma formação específica para se trabalhar com jovens e adultos. Essa constatação é expressa por outros autores como Ribeiro (1999), Arroyo (2006), Machado (2000), Kleiman (2000), Paiva (2004) e Oliveira (2001). Esse aspecto aponta para implicações inerentes à formação desse educador, desde reconhecer a realidade dos sujeitos da EJA, passando pela formulação de propostas curriculares coadunadas a essas realidades, indo até a criação de recursos didáticos que enriqueçam e estimulem a aprendizagem dos jovens e adultos.

Um aspecto extremamente importante a ser destacado nas quatro experiências analisadas é a relação entre teoria e prática durante a formação do educador. No Paranoá, Zé Peão e PROEF/UFMG, formar-se educador de jovens e adultos é, ao mesmo tempo, desenvolver atividades pedagógicas, dedicar tempo a estudos e reflexões permanentes sobre a prática (TARDIF, 2002). No caso do CMET Paulo Freire, em que a formação inicial já se realizou quando da graduação dos professores, mostrou-se indispensável e necessário o processo de atualização e olhar sobre 
a prática como atividade de formação continuada. A SMEd oferece, ao longo do ano, oito encontros de formação. Nesses encontros, reúnem-se todos os professores da rede municipal. Além dessa formação, toda semana os professores do CMET encontram-se com a equipe pedagógica e cultural da escola para formação em serviço. Esses encontros acontecem sempre às sextas-feiras e, para que os alunos não fiquem sem aula, foram organizadas oficinas variadas.

A seleção de candidatos para monitores-professores do PROEF é feita por meio de uma entrevista. Os selecionados participam de um curso de capacitação para trabalhar na educação de jovens e adultos, com duração média de uma semana. Ao longo do ano, acontecem, nas sextasfeiras, reuniões gerais, por área e por turma, que fazem parte da formação continuada dos educadores, possibilitando o diálogo entre formação docente (prática) e o aprendizado adquirido na universidade (teoria).

No Zé Peão, a formação ocorre ao longo do ano em reuniões semanais que desenvolvem o acompanhamento, a fundamentação por intermédio de questões teóricas e o planejamento de aulas com as educadoras, sob orientação da coordenação do projeto, em um processo de tratamento dos desafios da sala de aula. Durante a formação, acontecem seminários, elaboração de resumos e debates temáticos. Ao final, as educadoras planejam uma aula e são convidadas a conhecer um canteiro de obra, onde poderão desenvolver o que foi planejado. Assim, aqueles que assumem turmas passaram por discussões ligadas ao histórico da EJA e pelo estudo da metodologia de trabalho do projeto, integrada com a discussão de textos selecionados pela coordenação desse projeto.

A formação inicial no Paranoá é dada por meio de um curso de novos alfabetizadores, que acontece no início do ano letivo, e está dividida em três partes importantes: a primeira é conhecer a história do Paranoá, como surgiu e como foi fundado o Cedep; a segunda é como valorizar a história de vida de cada um, pois constitui parte importante para a alfabetização; e a terceira é "como fazer", o que, segundo os coordenadores entrevistados, é a parte mais complicada, pois nem sempre se torna claro para as alfabetizadoras o "como fazer". 


\section{Considerações finais}

O tema "especificidades na educação de jovens e adultos" é muito amplo. Podem-se trabalhar vários aspectos, como currículo, reflexão teórico-prática, tempos-espaços, diversidade de sujeitos, material didático e formação de educadores. Dedicamos nosso estudo sobre as especificidades da formação desse educador, sempre atentos às suas particularidades, pois "se esse perfil de educação de jovens e adultos não for bem conhecido, dificilmente estaremos formando um educador desses jovens e adultos" (ARROYO, 2006, p. 22).

Por intermédio da pergunta inicial: "Quais as especificidades da formação da EJA", procuramos selecionar propostas que nos auxiliassem a identificar as peculiaridades dessa formação. As observações de campo realizadas nos levaram à reflexão de que a história e o tempo de existência de cada proposta influenciavam na formação inicial e continuada oferecida aos seus educadores. Algumas enfocavam mais as questões políticas, de direitos e participação ativa, como o caso dos Projetos Escola Zé Peão e Paranoá; outras, como o PROEF, priorizavam as questões relacionadas ao aprendizado. Já o CMET tenta estabelecer um equilíbrio entre elas. Essas prioridades não significam que uma prejudique a outra, mas estão relacionadas à origem e à história de cada uma.

Preservando as particularidades de cada proposta, destacamos aspectos que consideramos influências do pensamento freireano, como as relações dialógicas entre educador e educando, tomando como ponto de partida para a ação pedagógica o respeito pelo conhecimento do sujeito.

Em todas as experiências foi possível perceber tanto conquistas e avanços quanto limites. No Zé Peão, conseguiu-se promover o aumento da participação dos trabalhadores no sindicato e nas aulas, além de proporcionar "uma contribuição para o soerguimento da autoestima e da dignidade do trabalhador, para o fortalecimento de sua identidade num coletivo de operários e como cidadãos que têm nome e não mais o dedão sujo de tinta" (IRELAND, 2005, p. 105). Entre os limites, encontra-se o cansaço dos trabalhadores, o espaço físico improvisado e a rotatividade dos professores.

A conquista dos moradores de permanecerem na região do lago Paranoá, apesar de várias tentativas de expulsão, representou uma vitória da comunidade, o que, posteriormente, resultou na construção de um 
espaço que seria a referência para seus moradores: a Associação de bairro, mais tarde Centro de Desenvolvimento do Paranoá. A institucionalização da educação de jovens e adultos na cidade de Porto Alegre não impediu os processos de criação pedagógica nesse campo (MOLL; VÍVAN, 2007). Os momentos de reflexões e práticas estão sempre presentes na recriação do fazer escolar do CMET, que, aliados ao sentimento de equipe e à cumplicidade de toda a comunidade escolar, colaboram para o desenvolvimento de seus trabalhos.

As atuais ações do PROEF são bem mais abrangentes que as iniciais. O que começou apenas como uma pesquisa sobre alfabetização, alcançou toda a educação básica para jovens e adultos, atendendo às demandas internas e externas à UFMG.

Este trabalho não esgotou as possibilidades de análise e pesquisa, mas permitiu levantar e desenvolver reflexões a respeito das especificidades da formação do educador de jovens e adultos. 


\section{REFERÊNCIAS}

ARROYO, Miguel González. Formar educadoras e educadores de jovens e adultos. In: SEMINÁRIO NACIONAL SOBRE FORMAÇÃO DO EDUCADOR DE JOVENS E ADULTOS. Belo Horizonte: Autêntica, 2006.

BEISIEGEL, Celso Rui. A política de educação de jovens e adultos analfabetos no Brasil. In: OLIVEIRA, Dalila Andrade (Org.). Gestão Democrática da educação. Petrópolis, RJ: Vozes. 1997. p. 239-241.

Di PIERRO, Maria Clara. Um balanço da evolução recente da educação de jovens e adultos no Brasil. Alfabetização e Cidadania. São Paulo, v. 17, p. 11-23, 2004.

FÁVERO, Osmar. Educação de jovens e adultos: passado de historias, presente de promessas. In: Educação de Jovens e Adultos na América Latina. São Paulo: Moderna, 2009.

FRADE, Érica Paula; EITERER, Carmem Lucia. Os processos de Formação e de Subjetivação Docente na EJA em Atuação na Extensão Universitária na UFMG. Revista Anagrama - Revista Interdisciplinar da Graduação. Ano 1, Edição 3, Março/Maio 2008. GIOVANETTI, Maria Amélia. A formação de educadores de EJA. Diálogos na EJA. Belo Horizonte: Autêntica, 2005.

HADDAD, Sérgio. Por uma nova cultura de Educação de Jovens e Adultos, um balanço de experiências de poder local. Novos caminhos em Educação de Jovens e Adultos - EJA. São Paulo: Global, 2007.

IRELAND, Timothy. Uma prática educativa com operários em construção. In: Construção Coletiva: Contribuições para a educação de Jovens e adultos. Brasília: UNESCO, MEC, RAAAB, 2005.

JESUS, Leila Maria de. A repercussão da atuação de educadores/as populares do CEDEP/UNB na escola publica do Paranoá-DF. Dissertação (mestrado em Educação) Faculdade de Educação - Universidade de Brasília, Brasília, 2007.

KLEIMAN, A. (Org.) O ensino e a formação do professor: alfabetização de jovens e adultos. Porto Alegre: Artes Médicas, 2000.

MACHADO, M.M. A prática e a formação de professores na EJA: uma análise de dissertações e teses produzidas no período de 1996 a 1998. In: REUNIÃO ANUAL DA ANPED, 23, 2000.

MARMOL, Mirian; MACIEL, Francisca Isabel Pereira. A Inserção dos Trabalhadores do Campus 2000 no Projeto de Ensino Fundamental de EJA/UFMG $1^{\circ}$ Segmento (PROEF-1). FaE/UFMG, 2002.(Mimeo.)

MOLL, Jaqueline; VIVIAN, Danise. Institucionalização e criação na EJA: perscrutando caminhos afirmativos no Centro Municipal dos Trabalhadores Paulo Freire em Porto Alegre. In: HADDAD, Sérgio. Novos Caminhos em Educação de Jovens e Adultos - EJA. São Paulo: Global, 2007.

OLIVEIRA, M. K. Jovens e Adultos como sujeitos de conhecimento e aprendizagem. In: RIBEIRO, Vera Masagão. Educação de Jovens e Adultos. Novos leitores, novas leituras. São Paulo: Ação Educativa, 2001.

OLIVEIRA, Marco Antonio. Alfabetização de Adultos na UFMG: uma experiência que deu certo. Disponível em:

<http://www.ich.pucminas.br/posletras/Producao $\% 20$ docente/Marco\%20Antonio/A lfabetizacao $\% 20 \mathrm{de} \% 20$ adultos $\% 20$ na $\% 20$ UFMG-2001.pdf $>$. Acessado em 01 de 
dezembro de 2009.

PAIVA, J. Educação de jovens e adultos: questões atuais em cenário de mudanças. In: OLIVEIRA, I. B.; PAIVA, J. Educação de jovens e adultos. Rio de Janeiro: DP\&A, 2004.

PEGO, Alison Leal; CAMPOS, Eliete dos Santos; OLIVEIRA, Gerlane Roberto de; MACIEL, Francisca Isabel Pereira. PROEF-1. $1^{\circ}$ Segmento: Possibilidades para a continuação de Estudos dos Alfabetizandos e Formação Docente dos graduandos. Disponível em: <http://www.ufmg.br/proex/arquivos/8Encontro/Educa_15.pdf>. Acessado em 01 de dezembro de 2009.

RIBEIRO, V. M. A formação de educadores e a constituição da educação de jovens e adultos como campo pedagógico. Educação \& Sociedade, Campinas, v. 20, n. 68, dez. 1999. SEJA, Serviço de Educação de Jovens e Adultos. Falando de Nós: o SEJA - Pesquisa Participante em Educação de Jovens e Adultos. Porto Alegre: Ed. Secretaria Municipal de Educação de Porto Alegre - Prefeitura de Porto Alegre, 1998.

SCHMELKES, Sylvia. Las necesidades básicas de aprendizaje de los jóvenes y adultos en América Latina. La educación de adultos y las cuestiones sociales. Antologia. Pátzcuaro, Michoacán, México. Paidéia. Latinoamericana, 2, 2008.

SOARES, Leôncio. O educador de jovens e adultos e sua formação. Educação em Revista, n. 47, p. 83-100, jun. 2008.

SOARES, Leôncio. A formação inicial do educador de jovens e adultos: um estudo da habilitação de EJA dos cursos de Pedagogia. In: GRACINDO, Regina Vinhaes. Educação como exercício de diversidade: estudos em campos de desigualdades sócio- educacionais. Brasília: Líber Livro, 2007. p. 89-103.

SOARES, Leôncio. Programa de Educação Básica de Jovens e Adultos. UFMG, 1996. (Mimeo.)

TARDIF, Maurice. Saberes docentes e formação profissional. Petrópolis, RJ: Vozes, 2002. http:/ / www.ceale.fae.ufmg.br/acao_educacional.php?catId=75\&txtId=70 http:/ / www.ceale.fae.ufmg.br/acao_educacional.php?catId=75\&txtId=70 


\section{NOTAS}

1 Entrevista realizada em 30/05/2009, no Projeto Escola Zé Peão, em João Pessoa.

2 Observação de campo realizada em maio de 2009.

3 Projeto de pesquisa Juventude, Escolarização e Poder Local, desenvolvido com apoio do CNPq e Fapesp no período de 2003-2006, investigação do caminho percorrido pelos municípios de seis regiões metropolitanas quanto à suas políticas públicas, realizando estudo de caso sobre experiências locais que fossem significativas por sua singularidade (HADDAD, 2007).

4 Entrevista realizada em 26 de agosto de 2009, no Cedep, Projeto Lago Paranoá.

5 Entrevista realizada em 28/10/2009 no CMET, em Porto Alegre.

6 SILVA, Álamo Pimentel Gonçalves. As narrativas identitárias das produções textuais em educação de jovens e adultos. ANPEd, GT18, 18 páginas 2007. A Palavra do Trabalhador foi uma produção da SMED Porto Alegre, no período de 1991 a 2001, em que foram editados dez números.

7 Entrevista realizada em 28/10/2009, no CMET, em Porto Alegre.

Recebido: 09/09/2010 Aprovado: 20/05/2011

Contato: Universidade Federal de Minas Gerais

Faculdade de Educação Avenida Antonio Carlos, 6627

Pampulha

CEP 31270-901

Belo Horizonte, MG

Brasil 